\title{
GEOGRAPHIC PATTERNS IN PLANT-POLLINATOR MUTUALISTIC NETWORKS
}

\author{
Jens M. OLESEN ${ }^{1,3}$ AND PEDRo JordanO ${ }^{2}$
}

\author{
${ }^{1}$ Department of Ecology and Genetics, University of Aarhus, Ny Munkegade Block 540, DK-8000 Aarhus, Denmark \\ ${ }^{2}$ Estación Biológica de Doñana, CSIC, Pab. Perú, Avda. M. Luisa S/N, E-41013 Sevilla, Spain
}

\begin{abstract}
Recent reviews of plant-pollinator mutualistic networks showed that generalization is a common pattern in this type of interaction. Here we examine the ecological correlates of generalization patterns in plant-pollinator networks, especially how interaction patterns covary with latitude, elevation, and insularity. We review the few published analyses of whole networks and include unpublished material, analyzing 29 complete plantpollinator networks that encompass arctic, alpine, temperate, Mediterranean, and subtropical-tropical areas. The number of interactions observed $(I)$ was a linear function of network size $(M)$ the maximum number of interactions: $\ln I=0.575+0.61 \ln M ; R^{2}=0.946$. The connectance $(C)$, the fraction of observed interactions relative to the total possible, decreased exponentially with species richness, the sum of animal and plant species in each community $(A+P): C=13.83 \exp [-0.003(A+P)]$. After controlling for species richness, the residual connectance was significantly lower in highland $(>1500 \mathrm{~m}$ elevation) than in lowland networks and differed marginally among biogeographic regions, with both alpine and tropical networks showing a trend for lower residual connectance. The two Mediterranean networks showed the highest residual connectance. After correcting for variation in network size, plant species were shown to be more generalized at higher latitude and lowland habitats, but showed increased specialization on islands. Oceanic island networks showed an impoverishment of potential animal pollinators (lower ratio of animal to plant species, $A: P$, compared to mainland networks) associated with this trend of increased specialization. Plants, but not their flower-visiting animals, supported the often-repeated statements about higher specificity in the tropics than at higher latitudes. The pattern of interaction buildup as diversity increases in pollination networks does not differ appreciably from other mutualisms, such as plant-seed disperser networks or more complex food webs.
\end{abstract}

Key words: food web; geographic variation; insects; interaction-web connectance; mutualism; networks; plant-animal interaction; pollination; specialization.

\section{INTRODUCTION}

Pollination interactions are among the most studied of all mutualisms. However, most of this research focuses on single plant species and their associated flower visitors or, at most, involves guilds of related plants or pollinators (Waser et al. 1996). Studies involving total communities of interacting plants and flower-visiting animals are much rarer. In 1987, Jordano analyzed the few community studies that were available at the time. He concluded that (1) facultative interactions of high generality are the rule; (2) the degree of connectedness of the mutualistic web covaries with species richness in ways similar to that of other food webs; and (3) most interactions are weak and, when considering the mutual effects of animals and plants, strongly asymmetric. He concluded that especially because of (1), research in interaction biology has to take place at the community level. However, this has rarely been done because, among other things, it requires labor-intensive sampling procedures, and several animal taxa pose taxo-

Manuscript received 14 February 2001; revised 10 January 2002; accepted 23 January 2002.

${ }^{3}$ E-mail: jens.olesen@biology.au.dk nomical difficulties. Several recent empirical studies, influential reviews, and pollination biology textbooks stress the generalized nature of pollination interactions (e.g., Feinsinger 1987, C. M. Herrera 1988, 1996, Ollerton 1996, 1998, Proctor et al. 1996, Waser et al. 1996, Elberling and Olesen 1999, Kanstrup and Olesen 2000, Olesen 2000, Ollerton and Watts 2000; but see Thompson 1994, Momose et al. 1998, Armbruster et al. 2000, Johnson and Steiner 2000, Rasmussen and Olesen 2000). Few of these studies, however, have attempted a quantification of generalization levels (Herrera 1996, Waser et al. 1996, Olesen 2000).

Discussions on generalization levels, of course, must be comparative. A flower-visiting species can only be termed a generalist in comparison to other pollinator species or to other kinds of mutualists or antagonists. A first discussion of the level of generalization in pollination soon requires a more formal macroecological analysis (Herrera 1996, Elberling and Olesen 1999, Magaard 1999, Kanstrup and Olesen 2000, Olesen 2000, Ollerton and Watts 2000, Rasmussen and Olesen 2000). Such an analysis requires some thought on how we should measure and express the level of generalization in pollination networks. At the moment, this 
conceptualization is in its very first phase (Johnson and Steiner 2000, Olesen 2000). Armbruster et al. (2000) distinguished between evolutionary and ecological specialization. The first category is defined as a process of evolving in the direction of more specialization, whereas the latter is a state and refers to having one to few interactions. Here, we are only speaking about ecological specialists and generalists. Janzen (1973) discussed generalization concepts briefly in the context of the tropical herbivore fauna. He stressed the importance of gathering data on the variation in relative fitness when a herbivore feed on different plant species. This applies to pollination interactions, too. Nutrient composition of nectar and pollen varies, as does the pollination effectiveness of individual flower-visiting animal species. Thus, studies of generalization level have to go beyond the mere counting of species interactions, or, as Janzen (1973:203) stated it, “. . . we cannot afford to forget that herbivores do not eat Latin binomials." Here, however, we only use the number of interactions between species of flowering plant and flower visitors as our measure of generalization level, because that is what is available in pollination biology at present. Thus, we are still forced to ignore that fact that plants are not pollinated by Latin binomials. Jordano's (1987) review had access to only one study that included the total flora and the flower-visiting fauna within a habitat (J. Herrera 1988). The rest of Jordano's database included various pollinator guilds and their mutualists (also see Waser et al. 1996). Since then, several studies of total networks have been published or are in press (Olesen 2000; J. M. Olesen and P. Jordano, unpublished data).

Here we describe how the generalization level varies among a set of 29 community-level networks of plantpollinator interactions, and we analyze patterns of covariation with species richness, latitude, elevation, and insularity. Specifically, we address the following questions. Are interactions more specialized in the tropics than at higher latitudes? Do plant-pollinator interaction networks show higher specialization in island environments when compared to mainland? Are there predictable patterns of covariation between species richness and generalization level in plant-pollinator interactions?

\section{Methods}

\section{Properties of pollination mutualistic networks}

A pollination network is here defined as a matrix $\mathbf{R}$ describing trophic and reproductive interactions between communities of $P$ flowering plant species and $A$ flowervisiting animal species within a well-defined habitat:

$$
\mathbf{R}=\left[r_{i j}\right]_{A P}
$$

where

$$
r_{i j}= \begin{cases}1 & P_{i} R A_{j} \\ 0 & \text { otherwise }\end{cases}
$$

Thus this matrix has nonzero $r$ elements wherever animals harvest pollen, nectar, or receive other benefits from flower visitation, or wherever plants are pollinated or visited by flower-visiting animals. Here we only consider binary data, i.e., the presence or absence of an interaction in such a binary network, analogous to other types of networks, either biotic (Cohen 1978) or abiotic (Wasserman and Faust 1994, Watts and Strogatz 1998). Typically, mutualistic networks (Jordano 1987) are two-mode networks consisting of two sets of entities, i.e., plant and animal species. The units in this network (species) are connected in a bipartite graph whenever they interact (Wasserman and Faust 1994). In 18 out of the 29 networks included in the present analysis, authors quantified dependency in number of visiting encounters. The value can be used to estimate the relative strength of an interaction or the level of dependency between a pair of mutualists. We report detailed analyses of mutual dependency patterns in subsequent papers.

Network size $(M)$ is given as

$$
M=A P
$$

where $A$ and $P$ are the total number of interacting animal and plant species in the habitat, respectively. $M$ is thus a species richness, species density, or biodiversity measure indicating the maximum number of observable interactions. Generalization level in networks may be compared both at the species and the network level. Although sophisticated measures of interaction structure have been proposed (Ramirez 1989), most studies focus on a few descriptors. We use two measures at the network level, the total number of interactions in the network $(I)$ and the connectance $(C)$ :

$$
C=100 I / M \text {. }
$$

Connectance is the percentage of all possible interactions within a network that are actually established, i.e., it is a scale- or $M$-independent measure of the generalization level of a network (Jordano 1987). In addition, we use two measures at the species level: mean number of interactions across animal species $\left(L_{\mathrm{m}}\right.$, linkage level),

$$
L_{\mathrm{m}}=I / A
$$

and mean number of interactions across plant species,

$$
L_{\mathrm{n}}=I / P \text {. }
$$

We analyzed the dependency of these parameters on $M$, latitude, altitude, and insularity (i.e., whether the study took place on an oceanic island or in a mainland, or land-bridge island). Except for latitude, all variables were ln-transformed in order to achieve normality and a constant variance, and $C$ was angular-transformed. To examine the relationships between network parameters and insularity, island and mainland networks were coded with dummy variables, values of 0.5 and 1.0, respectively. Pairwise relationships among variables 
TABLE 1. Characteristics of complete plant-pollinator networks included in the present study.

\begin{tabular}{lll}
\hline \hline \multicolumn{1}{c}{ Source } & \multicolumn{1}{c}{ Locality } & \multicolumn{1}{c}{ Habitat } \\
\hline 1) Arroyo et al. (1982) & Cordon del Copo, Chile & subandean scrub \\
2) Arroyo et al. (1982) & Cordon del Copo, Chile & cushion zone \\
3) Arroyo et al. (1982) & Cordon del Copo, Chile & subnival zone \\
4) Elberling and Olesen (1999) & Latnjajaure, Abisko, Sweden & rocky slope \\
5) Elberling and Olesen, unpublished data & Zackenberg, Greenland & tundra \\
6) Eskildsen et al., unpublished data & Ile aux Aigrettes, Mauritius & coralline island \\
7) J. Herrera (1988) & Doñana Nat. Park, Spain & scrub \\
8) Hocking (1968) & Hazen Camp, Canada & tundra \\
9) Inoue et al. (1990) & Kibune, Kyoto, Japan & mixed forest \\
10) Inouye and Pyke (1988) & Snowy Mountains, Australia & scrub/snow gum \\
11) Kakutani et al. (1990) & Kyoto City, Japan & urban area \\
12) Kato and Miura (1996) & Nakaikemi, Tsuruga, Japan & marsh \\
13) Kato et al. (1990) & Ashu, Kyoto, Japan & beech forest \\
14) Kato et al. (1993) & Mt. Kushigata, Japan & subalpine forest/meadow \\
15) Kevan (1970) & Hazen Camp, Canada & tundra \\
16) McMullen (1993) & Pinta, Galápagos Isles & volcanic southern slope \\
17) Mosquin and Martin (1967) & Melville Island, Canada & tundra valley \\
18) J. M. Olesen, unpublished data & Hestehaven, Denmark & wasteground \\
19) Olesen et al. (2002b) & Garajonay, Gomera, Spain & laurel forest \\
20) J. M. Olesen, unpublished data & Hestehaven, Denmark & beech-oak forest \\
21) J. M. Olesen, unpublished data & Hestehaven, Denmark & salt bog \\
22) Olesen et al. (2002a) & Flores, Acores, Portugal & coastal cliff \\
23) Percival (1974) & Southeastern Jamaica & coastal scrub \\
24) Petanidou (1991) & Daphni, Greece & phrygana \\
25) Primack (1983) & Arthur's Pass, New Zealand & grassland \\
26) Primack (1983) & Cass, New Zealand & grassland \\
27) Primack (1983) & Craigieburn, New Zealand & grassland \\
28) Ramirez (1989) & Canaima National Park, Venezuela & open forest \\
29) Schemske et al. (1978) & Brownfield, Illinois, USA & deciduous forest \\
\hline
\end{tabular}

Note: Abbreviations are: $A$, number of animal species; $P$, number of plant species; $M$, network size $(=A P) ; I$, number of interactions recorded; $C$, connectance $(C=100 \mathrm{I} / \mathrm{M})$.

were analyzed by least squares regression with permutation tests, and significance levels were estimated with $N=5000$ resamplings (Manly 1991, Legendre et al. 1994).

\section{Potential methodological biases}

A set of complete pollination networks extracted from literature and our own research were collated and analyzed (Table 1). They originated from highly disparate sites all over the world. A serious shortcoming of the data set was the lack of information about pollination networks in tropical lowland rain forests (but see Kress and Beach 1994, Kato 1996, Momose et al. 1998, Kanstrup and Olesen 2000). In these habitats, 98-99\% of the flowering species may have biotic pollination (Bawa 1990).

In each publication, the data set was reanalyzed; some of the estimates presented here may differ from original values given by authors. Blackburn and Gaston (1998) considered a set of methodological issues that have to be addressed in such a macroecological analysis (sensu Brown 1995:6), and some of these issues will be discussed. The networks were biogeographically biased and, for that reason, could not be regarded as completely independent data points. Arctic-alpine networks dominated and the tropical lowland was completely missing. The flower-visiting animal communities in the tropical lowland studies of Kress and Beach
(1994), Kato (1996), and Momose et al. (1998) were not sufficiently resolved taxonomically to be included. However, we assume that relationships found in this paper can be extrapolated to networks at all latitudes, and that similar patterns are present in both the Northern and Southern Hemisphere. These assumptions are, however, debatable (Blackburn and Gaston 1996).

In network studies, information on species and interactions is often pooled across the entire study season, study period, or a major part of it (cumulative studies sensu Schoenly and Cohen [1991], or aggregated studies). As a consequence, phenological overlap between some of the animal and plant species may be low or even nonexistent, e.g., as in Reader (1975). The importance of this fact is often ignored. In the present review, it becomes a serious pitfall. Petanidou (1991) is a remarkable exception, because she considered the continuous turnover of interactions throughout four successive years.

Most studies in field ecology only last for one season or one year. This was true also for most of the present pollination studies. However, it is well known that the flower-visitor fauna in a habitat may vary tremendously in composition between seasons (e.g., C. M. Herrera 1988). In addition, we would expect a tendency to census a smaller proportion of all interactions within a network with increasing $M$, because a diminishing observation time becomes available to each species. On 
TABle 1. Extended.

\begin{tabular}{|c|c|c|c|c|c|c|}
\hline Latitude & Altitude (m) & $A$ & $P$ & $M$ & $I$ & $C$ \\
\hline $33^{\circ} \mathrm{S}$ & $2200-2600$ & 101 & 84 & 8484 & 361 & 4.3 \\
\hline $33^{\circ} \mathrm{S}$ & $2700-3100$ & 64 & 43 & 2752 & 196 & 7.1 \\
\hline $33^{\circ} \mathrm{S}$ & $3200-3600$ & 25 & 36 & 900 & 81 & 9.0 \\
\hline $68^{\circ} \mathrm{N}$ & 985 & 118 & 24 & 2832 & 242 & 8.5 \\
\hline $75^{\circ} \mathrm{N}$ & 25 & 76 & 31 & 2356 & 456 & 19.4 \\
\hline $20^{\circ} \mathrm{S}$ & 5 & 13 & 14 & 182 & 52 & 28.6 \\
\hline $37^{\circ} \mathrm{N}$ & 25 & 179 & 26 & 4654 & 412 & 8.9 \\
\hline $82^{\circ} \mathrm{N}$ & 500 & 81 & 29 & 2349 & 179 & 7.6 \\
\hline $35^{\circ} \mathrm{N}$ & $300-740$ & 840 & 112 & 94080 & 1876 & 2.0 \\
\hline $36^{\circ} \mathrm{S}$ & $1860-2040$ & 81 & 36 & 2916 & 253 & 8.7 \\
\hline $35^{\circ} \mathrm{N}$ & 60 & 315 & 113 & 35595 & 774 & 2.2 \\
\hline $36^{\circ} \mathrm{N}$ & 45 & 187 & 64 & 11968 & 430 & 3.6 \\
\hline $35^{\circ} \mathrm{N}$ & $620-959$ & 679 & 91 & 61789 & 1193 & 1.9 \\
\hline $36^{\circ} \mathrm{N}$ & 1850 & 356 & 90 & 32040 & 865 & 2.7 \\
\hline $82^{\circ} \mathrm{N}$ & 100 & 91 & 20 & 1820 & 190 & 10.4 \\
\hline $1^{\circ} \mathrm{S}$ & $15-580$ & 22 & 10 & 220 & 27 & 12.3 \\
\hline $75^{\circ} \mathrm{N}$ & 100 & 18 & 11 & 198 & 38 & 19.2 \\
\hline $56^{\circ} \mathrm{N}$ & 5 & 82 & 26 & 2132 & 249 & 11.7 \\
\hline $28^{\circ} \mathrm{N}$ & 1200 & 55 & 29 & 1595 & 145 & 9.1 \\
\hline $56^{\circ} \mathrm{N}$ & 5 & 42 & 8 & 336 & 79 & 23.5 \\
\hline $56^{\circ} \mathrm{N}$ & 5 & 40 & 10 & 400 & 72 & 18.0 \\
\hline $38^{\circ} \mathrm{N}$ & 10 & 12 & 10 & 120 & 30 & 25.0 \\
\hline $19^{\circ} \mathrm{N}$ & 5 & 36 & 61 & 2196 & 178 & 8.1 \\
\hline $38^{\circ} \mathrm{N}$ & $135-215$ & 666 & 131 & 87246 & 2933 & 3.4 \\
\hline $43^{\circ} \mathrm{S}$ & 900 & 60 & 18 & 1080 & 120 & 11.1 \\
\hline $43^{\circ} \mathrm{S}$ & $600-800$ & 139 & 41 & 5699 & 374 & 6.6 \\
\hline $43^{\circ} \mathrm{S}$ & $1600-1800$ & 118 & 49 & 5782 & 346 & 6.0 \\
\hline $6^{\circ} \mathrm{N}$ & 1350 & 46 & 47 & 2162 & 151 & 7.0 \\
\hline $40^{\circ} \mathrm{N}$ & 300 & 33 & 7 & 231 & 65 & 28.1 \\
\hline
\end{tabular}

a real web, Goldwasser and Roughgarden (1997) simulated variation in sampling effort and found that its impact on web properties was profound. They stressed that detection of interactions lags far behind detection of species, biasing most properties of a web. This might be a minor problem in pollination networks because animal and plant species are not included before they make a visit to a plant species or receive a visit from an animal species, respectively.

Pollination networks are difficult to delimit spatially, e.g., in Feinsinger and Colwell (1978), where hummingbirds visit flowers over several altitudinal zones, or in Snow and Snow (1972), where an entire valley with probably many different habitats is treated as an entity. The reviewed studies spanned study areas of 0.01-30 ha, but several studies did not give precise plot size. This variation in methods among studies constrained the comparative analysis.

In classic food web literature, taxonomic resolution varies. Taxonomic species, operational taxonomic units, or researcher-identified species are being lumped together into "trophic species" or "kinds of organisms" (e.g., Cohen 1978). Species sharing predator or prey may be grouped together and counted as a single matrix entry, or species simply may be grouped on their resemblance in behavior and morphology. In some of the pollination studies, a few of the most taxonomically difficult pollinator groups (e.g., Lasioglossum bees in Inouye and Pyke [1988]) or groups suspected to be of minor ecological importance were not always resolved to species level. Such an incomplete breakup of certain taxa is a major problem to an analysis such as the present one because it must, to some extent, affect generalization level. However, Hall and Raffaelli (1991) and Sugihara et al. (1997), among others, have shown that aggregation of taxonomic and trophic entities does not markedly change the behavior of web properties. In particular, a high number of trophically equivalent taxa, such as in this study, with only two major roles (pollinated plants and pollinators), seems to reduce the scaling sensitivity of web properties (Jordano 1987). Food chain length, on the other hand, is sensitive to aggregation.

Most food web catalogues have been criticized for being incomplete and tending to produce artificial patterns (Martinez 1991, Polis 1991). However, the networks analyzed here have only two trophic levels and represent a taxonomically and ecologically more homogeneous set of studies than food webs in general. Therefore, in spite of all the caveats, we believe that the approach is valid and of interest to a discussion of species assembly processes, biogeographic variation in generalization, coevolution, and biodiversity (Waser et al. 1996).

The size and structure of a pollination network may have both historical and recent ecological determinants (Ricklefs and Schluter 1993). However, the first has rarely been addressed. Some lineages might have spe- 


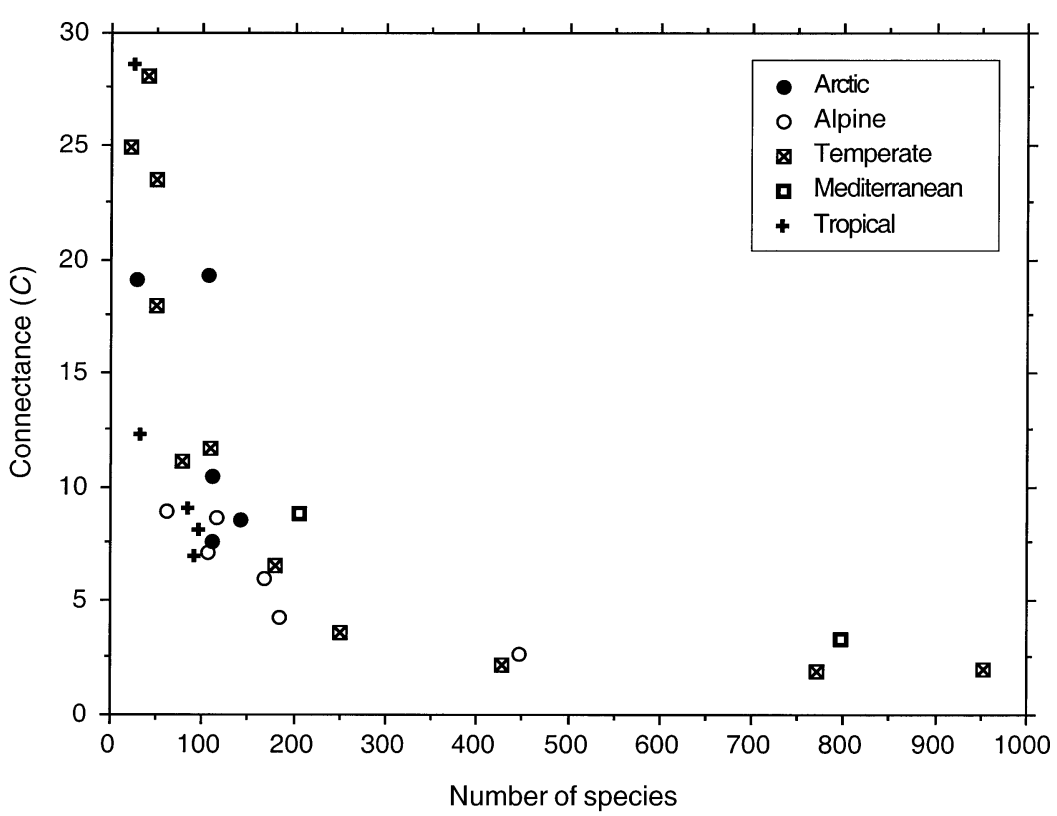

FIG. 1. Relationship between connectance $(C)$ and species richness, the total number of animal and plant species $(A+$ $P$ ), in plant-pollinator mutualistic networks from different biogeographic regions (see Table 1).

ciated considerably in certain regions and thus contributed disproportionately to the communities. Phylogenetic relatedness might generate spurious patterns between generalization level and network size, latitude, and altitude. However, incomplete knowledge, especially of insect phylogeny, precludes phylogenetic correction of the results in the present study. Despite these shortcomings, we believe that the results are robust as a preliminary approximation to the pattern of connectedness in the few complete plant-pollinator networks presently available.

\section{RESULTS}

Twenty-three papers included data on 29 pollination networks between all flowering plant and flower-visitor species within a habitat (Table 1). They encompassed a total of 4575 animal species and 1271 plant species. The networks (Table 1) belonged to five broadly defined biogeographical categories (numbers refer to entries in Table 1): arctic $(4,5,8,15,17)$, alpine $(1-3$, $10,14,27)$, temperate $(9,11-13,18,20-22,25-26$, 29), Mediterranean $(7,24)$, and subtropical-tropical (6, $16,19,23,28)$. They included five oceanic island networks and 24 mainland networks (including the New Zealand [25-27] ones as mainland).

Flower-visiting animals $(A)$ and flowering plants $(P)$, respectively, had a mean, median, and (range) of 158 , 81, (12-840) and 44, 35, (7-131) species (Table 1). The number of network interactions $(I)$ varied between 27 and 2933 (mean 426, median 626; Table 1), and its positive relationship with network size $(M)$ could be approximated, after transformation, by a log-log linear function $\left(\ln I=0.575+0.61 \ln M ; R^{2}=0.946\right)$. Con- nectance $(C)$ varied between $2 \%$ and $29 \%$ (mean $11 \%$, median $9 \%$; Table 1 ), and decreased exponentially with total number of species $(A+P), C=13.83$ $\exp [-0.003(A+P)] ; R^{2}=0.616$ (Fig. 1). There was a marginal trend for $C$ to differ among biogeographic regions when accounting for differences in species richness $(A+P)(F=2.73$, df $=3,21, P=0.053$; Fig. 1). Connectance, $C$, decreased with $M\left(R^{2}=0.811\right.$; Fig. 2), with no difference among biogeographic zones $(F=0.79$, df $=3,21, P>0.20)$. In addition, $L_{\mathrm{n}}$ (mean interactions across plant species) increased with $M\left(R^{2}\right.$ $=0.341$ ), whereas $L_{\mathrm{m}}$ (mean interactions across animal species) did not $\left(R^{2}=0.032\right.$; Table 2$)$.

Network properties may depend upon network size, $M$, and its effect may be controlled for by doing regression analysis on residuals (Bengtsson 1994) or by partialling out the effects of $M$ in multiple regression analyses. We accounted for differences in $M$ by incorporating this variable into a multiple regression when including latitude, altitude, and insularity as independent variables (Table 2 ). The studies spanned a wide latitudinal range from $1^{\circ}$ to $82^{\circ}$ and included both the northern and southern hemispheres. However, 16 of the networks fell within the range from $33^{\circ}$ to $43^{\circ}(\mathrm{N}$ or S latitude). When accounting for variation in network size $(M), C$ increased marginally with latitude $\left(R_{M \text { Lat }}^{2}=\right.$ $0.829, t=1.67, P_{\text {Lat }}=0.05$ for the partial effect of latitude), and decreased with altitude $\left(R_{\text {MAlt }}^{2}=0.851, t\right.$ $\left.=-2.64, P_{\text {Alt }}<0.005\right)$, whereas insularity had no effect $\left(R_{M \mathrm{Isl}}^{2}=0.818, t=0.65, P_{\mathrm{Isl}}=0.15\right.$; Table 2, Fig. $2)$. The number of interactions $(I)$ also increased with latitude $\left(R_{M \text { Lat }}^{2}=0.957, t=2.55, P_{\text {Lat }}<0.01\right)$ and decreased with altitude $\left(R_{M \text { Alt }}^{2}=0.953, t=-1.91, P_{\text {Alt }}\right.$ 

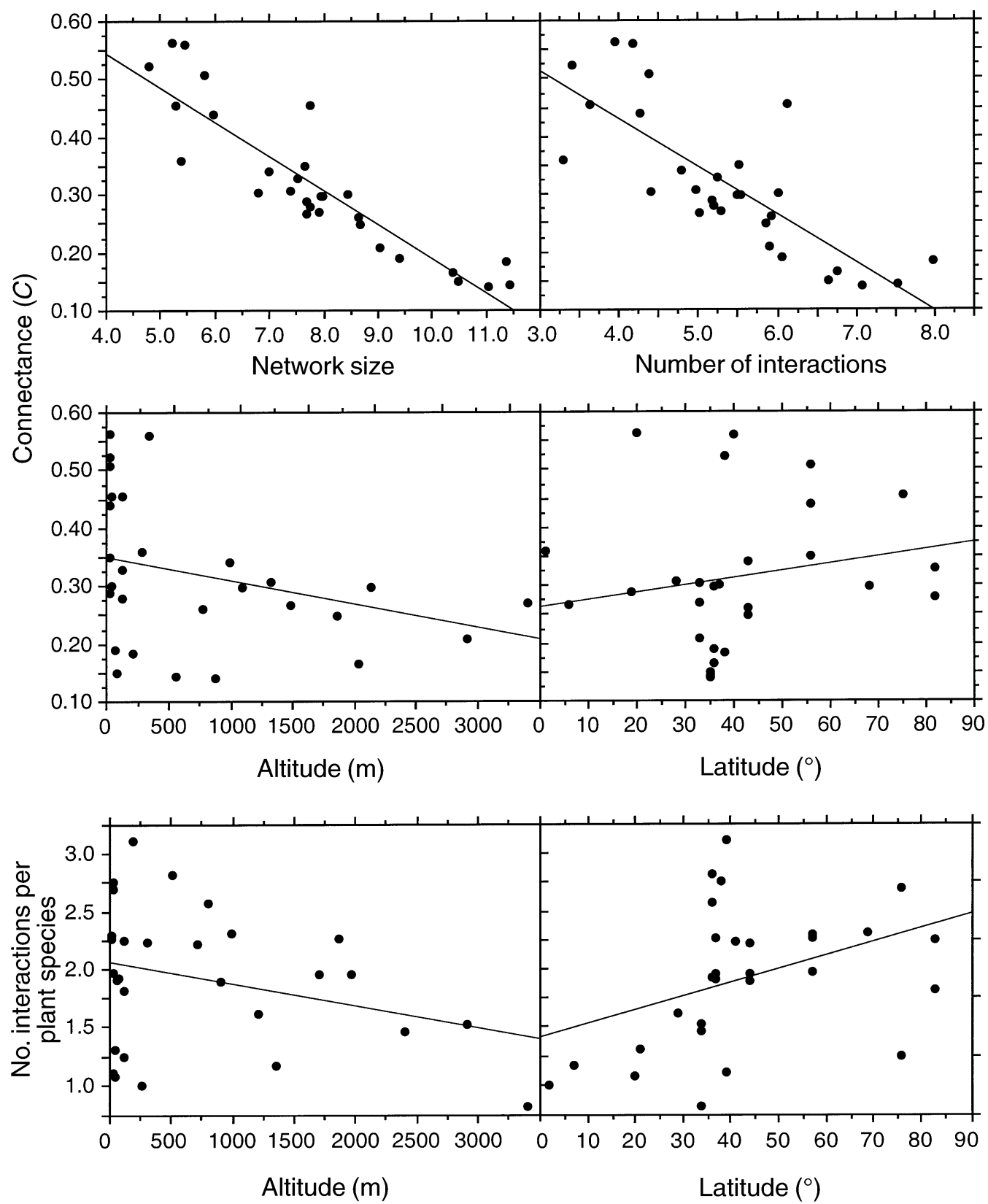

FIG. 2. Relationships between connectance $(C)$ and different parameters of plant-pollinator mutualistic networks: network size $(M), C=0.783-0.059 M\left(R^{2}=0.811\right)$; number of interactions $(I), C=0.762-0.083 I\left(R^{2}=0.625\right)$; number of interactions per animal species $\left(L_{\mathrm{m}}\right), C=0.327-0.011 L_{\mathrm{m}}\left(R^{2}=0.001\right)$; altitude $(E), C=0.350-4.409 \times 10^{-5} E\left(R^{2}=\right.$ $0.118)$; and latitude $(L), C=0.265+0.001 L\left(R^{2}=0.040\right)$. Also shown are the relationships between number of interactions per plant species $\left(L_{\mathrm{m}}\right)$ and altitude $(E), L_{\mathrm{n}}=2.056-1.897 \times 10^{-4} E\left(R^{2}=0.092\right)$; and latitude $(L), L_{\mathrm{n}}=1.418+0.012 L$ $\left(R^{2}=0.156\right)$. For all regressions, variables $M, I, L_{\mathrm{m}}$, and $L_{\mathrm{n}}$ were $\ln$-transformed, and $C$ was angular-transformed as arcsine $(C / 100)^{1 / 2}$. These equations do not account for differences in network size, $M$ (see Table 2).

$=0.03)$, and insularity had no effect $\left(R_{M \mathrm{ss}}^{2}=0.043, t\right.$ $=1.25, P_{\text {Isl }}=0.30$; Table 2$)$. The number of interactions per animal species $\left(L_{\mathrm{m}}\right)$ did not change with latitude, altitude, or insularity $\left(R^{2}<0.054, t<0.80, P\right.$ $>0.20$ in all cases; Table 2$)$. In contrast, the number of interactions per plant species $\left(L_{\mathrm{n}}\right)$ increased significantly with latitude $\left(R_{M \text { Lat }}^{2}=0.533, t=3.27, P_{\text {Lat }}=\right.$
0.002; Table 2), decreased with altitude $\left(R_{M \text { Alt }}^{2}=0.504\right.$, $t=-2.92, P_{\text {Alt }}=0.004$; Table 2), and also decreased in island environments $\left(R_{M \mathrm{Isl}}^{2}=0.169, t=2.14, P_{\mathrm{Isl}}=\right.$ 0.02; Table 2).

After controlling for variation in species richness $(A$ $+P)$, the residual connectance was significantly lower in highland ( $>1500 \mathrm{~m}$ elevation, the category "al- 
TABLE 2. Summary of results for least-squares regressions between network variables; significance was tested by permutation with $N=5000$ iterations.

\begin{tabular}{lcccc}
\hline \hline \multicolumn{1}{c}{ Network parameter } & $M$ & Latitude & Altitude & Insularity \\
\hline Connectance $(C)$ & $-0.9007^{*} * *$ & $0.1353^{* * *}$ & $-0.2027^{* *}$ & $0.0904^{\mathrm{NS}}$ \\
No. interactions $(I)$ & $0.9727^{*} * *$ & $0.1039^{*} *$ & $-0.0826^{*}$ & $0.0458^{\mathrm{NS}}$ \\
No. interactions per plant sp. $\left(L_{\mathrm{n}}\right)$ & $0.5840^{* * *}$ & $0.3572^{*} *$ & $-0.3141^{* *}$ & $0.3768^{*}$ \\
No. interactions per animal sp. $\left(L_{\mathrm{m}}\right)$ & $0.1796^{\mathrm{NS}}$ & $-0.0567^{\mathrm{Ns}}$ & $0.1517^{\mathrm{NS}}$ & $-0.1100^{\mathrm{NS}}$ \\
\hline
\end{tabular}

Notes: Values in column 2 are standardized regression coefficients. Network size, $M$, was included in the regressions for latitude, altitude, and insularity to correct for differences in network size. Values in columns 3-5 are thus standardized partial regression coefficients. $C$ was angular transformed prior to analyses; other variables were $\ln$-transformed.

$* P<0.05$; ** $P<0.01$; *** $P<0.001$; NS, nonsignificant; all with Bonferroni correction.

pine") than in lowland networks $(F=4.49$, df $=2$, $27, P=0.04$; Fig. 3$)$ and differed marginally among biogeographic regions $(F=2.71, \mathrm{df}=4,24, P=0.05$; Fig. 3). Both alpine and tropical networks showed a trend for lower residual connectance, after controlling for variation in species richness. The two Mediterranean networks showed the highest residual connectance.

\section{DISCUSSION}

The level of connectedness in complete communities of plant-pollinator mutualists decreased with increasing species richness in a way similar to that previously reported for sections of mutualistic networks (Jordano 1987) or other biotic networks (e.g., Cohen 1978, Sugihara et al. 1989). Our comparative analysis showed that, after correcting for variation in network size, connectance only decreased marginally toward the tropics, but decreased highly significantly with altitude. Corrected connectance did not vary between island and mainland networks. After correcting for variation in network size, plant species were shown to be more generalized at higher latitude and lowland habitats, and showed increasing specialization on islands. The number of interactions of an animal species was not affected significantly by these three biogeographical variables.

Thus plants, but not their flower-visiting animals, support the often-repeated statements about higher specificity in the tropics than at higher latitudes. These results, however, hide a lot of variation. Different plant and animal groups may behave very differently and constitute very different proportions of the total communities at the different sites (Herrera 1996, Olesen 2000). For example, Elberling and Olesen (1999) showed that the relative frequencies of the four major pollinator orders changed latitudinally: bees were more common at low latitudes, whereas dipterans dominated at high latitudes. Michener (1954), however, showed that bees did not vary in their generalization level with latitude. Thus a next step would be a macroecological analysis of the major flower-visitor orders, families, or genera, and the major plant families, separately.

Our study revealed a marked trend for decreasing plant generalization level in island environments, independent of any parallel trend in network size. An im- poverishment of potential animal pollinators on oceanic island environments is associated with this trend: island networks showed a markedly lower ratio of animal to plant species $(A: P)$ than mainland networks. Decreased island generalization for plants involves visitation by a narrow range of distinct taxonomic groups, often including taxa such as reptiles or passerine birds that are not considered pollinators on mainland environments ( $\mathrm{J}$. M. Olesen and A. Valido, unpublished manuscript). Our finding is the general trend. However, specialized main-

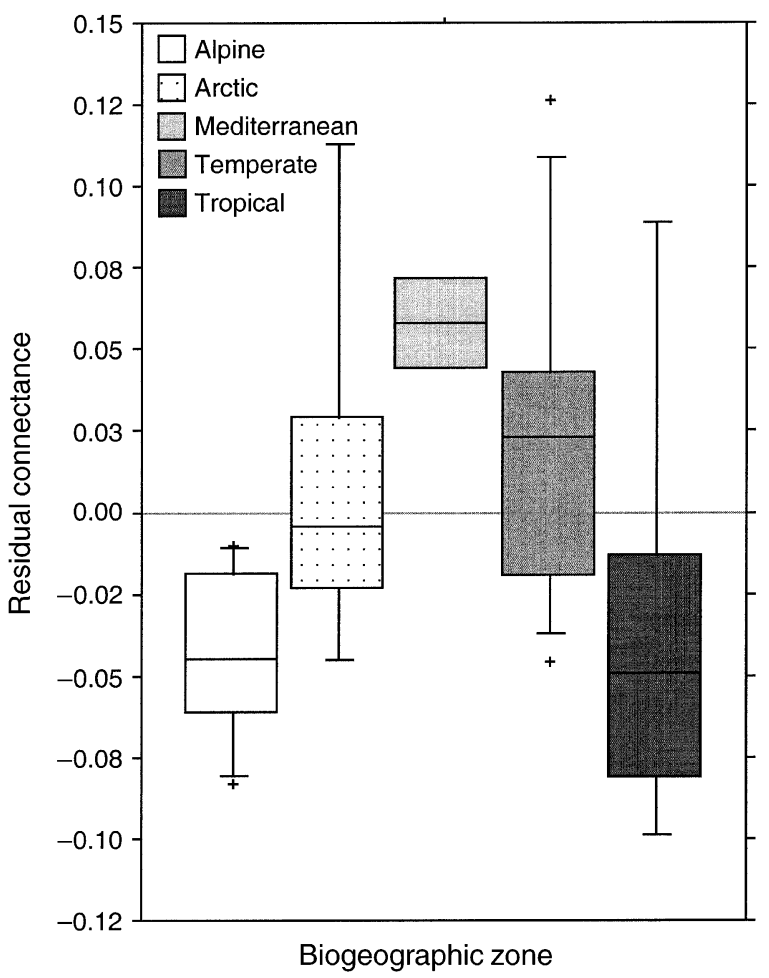

FIG. 3. Differences in connectance, after correcting for differences in network size $(M)$ among plant-pollinator networks from different biogeographic regions and located at different elevations (see Table 1). Highland is equal to "alpine." The median is marked by the center horizontal line splitting the data in halves, and the upper and lower hinges (the edges of the box) split the remaining halves in half again; outliers, designated + , lie between the upper hinge and 1.5 (upper hinge - lower hinge). 
land clades of plants are reported to evolve generalist clades on islands (Armbruster and Baldwin 1998).

In plant-pollinator mutualistic networks, species are each other's niches. If more plant species accumulate in an area, the spectrum of resources to flower-visiting animals is increased, too. Whittaker (1977) even called organic diversity self-augmenting. As shown in this study, the local level of species richness affects individual species and their biotic interactions. However, it is unclear how this occurs. If tropical habitats are saturated with species, their higher density of species should cause more interspecific competition, reduce niche overlap, and cause species to become more specialized. Janzen (1973) regarded tropical communities as "full." He thus assumed that the size of the community is determined by energy availability and competition. This was supported in our present study by the plants, but not by their flower-visiting animals. However, if the "tropics are not full, competition is irrelevant" (MacArthur 1972:219). Thus, in spite of the high diversity of flower-visiting animals in the tropics, the animals' food plant niche dimension may not be "full." A higher diversity of flower-visiting animals may not necessarily result in more specialization if the spectrum of exploited resources is increased concordantly (MacArthur 1972:222). A different picture emerged when we compared island and mainland networks. Plants responded to insularity by becoming less generalized, whereas the animal generalization level was unrelated to insularity. Thus, decreased latitude and insularity had the same effects.

Our approach illustrates the fact that extensive generalization in plant-pollinator interactions is the rule rather than the exception (Waser et al. 1996), and demonstrates that very few plant or pollinator taxa are indeed specialized. Moreover, the pattern of increasing interactions as diversity in pollination networks increases does not seem to differ appreciably from other mutualisms such as plant-disperser networks (Jordano 1987), or from more complex food webs. Endorsing the plea of Waser et al. (1996), we certainly need more community-wide studies to address the intricacies of plant-pollinator networks. However, a more thorough analysis of existing networks using new methodologies and concepts would probably be even more productive in our efforts to understand the ecology and evolution of networks and biological complexity.

\section{ACKNOWLEDGMENTS}

We thank R. Primack and P. Kevan for information on literature and additional information about their own community studies. Discussions with Jordi Bascompte and Carlos Melián were very helpful during the final stages of the manuscript. The study was supported by the Danish Natural Science Research Council (\#94-0163-1 to J.M. Olesen) and the Spanish Ministerio de Ciencia y Tecnología (BOS2000-1366C02-01 to P. Jordano).

\section{Literature Cited}

Armbruster, W. S., and B. G. Baldwin. 1998. Switch from specialized to generalized pollination. Nature 394:632.
Armbruster, W. S., C. Fenster, and M. R. Dudash. 2000. Pollination "principles" revisited: specialisation, pollination syndromes, and the evolution of flowers. Pages 179-200 in Ø. Totland, W. S. Armbruster, C. Fenster, U. Molau, L. A. Nilsson, J. M. Olesen, J. Ollerton, M. Philipp, and J. Ågren, editors. Scandinavian Association for Pollination Ecology honours Knut Fægri. Norwegian Academy of Science and Letters 39, Oslo, Norway.

Arroyo, M. T. K., R. Primack, and J. Armesto. 1982. Community studies in pollination ecology in the high temperate Andes of Central Chile. I. Pollination mechanisms and altitudinal variation. American Journal of Botany 69:82-97.

Bawa, K. S. 1990. Plant-pollinator interactions in tropical rain forests. Annual Review of Ecology and Systematics 21:399-422.

Bengtsson, J. 1994. Confounding variables and independent observations in comparative analyses of food webs. Ecology 75:1282-1288.

Blackburn, T. M., and K. J. Gaston. 1996. Abundance-body size relationships: the area you census tells you more. Oikos 75:303-309.

Blackburn, T. M., and K. J. Gaston. 1998. Some methodological issues in macroecology. American Naturalist 151: 68-83.

Brown, J. H. 1995. Macroecology. University of Chicago Press, Chicago, Illinois, USA.

Cohen, J. E. 1978. Food webs and niche space. Princeton University Press, Princeton, New Jersey, USA.

Elberling, H., and J. M. Olesen. 1999. The structure of a high latitude plant-pollinator system. The dominance of flies. Ecography 22:314-323.

Feinsinger, P. 1987. Approaches to nectarivore-plant interactions in the New World. Revista Chilena de Historia Natural 60:285-319.

Feinsinger, P., and R. K. Colwell. 1978. Community organization among neotropical nectar-feeding birds. American Zoologist 18:779-795.

Goldwasser, L., and J. Roughgarden. 1997. Construction and analysis of a large Caribbean food web. Ecology 74:12161233.

Hall, S. J., and D. Raffaelli. 1991. Food-web patterns: lessons from a species-rich web. Journal of Ecology 60:823-842.

Herrera, C. M. 1988. Variation in mutualisms: the spatiotemporal mosaic of a pollinator assemblage. Biological Journal of the Linnean Society 35:95-125.

Herrera, C. M. 1996. Floral traits and plant adaptation to insect pollinators: a devil's advocate approach. Pages 6587 in D. G. Lloyd and S. C. H. Barrett, editors. Floral biology. Chapman and Hall, New York, New York, USA.

Herrera, J. 1988. Pollination relationships in Southern Spanish Mediterranean shrublands. Journal of Ecology 76:274-287.

Hocking, B. 1968. Insect-flower association in the high Arctic with special reference to nectar. Oikos 19:359-388.

Inoue, T., M. Kato, T. Kakutani, T. Suka, and T. Itino. 1990. Insect-flower relationship in the temperate deciduous forest of Kibune, Kyoto: an overview of the flowering phenology and the seasonal pattern of insect visits. Contributions of the Biological Laboratory, Kyoto University 27:377-463.

Inouye, D. W., and G. H. Pyke. 1988. Pollination biology in the Snowy Mountains of Australia: comparisons with montane Colorado. Australian Journal of Ecology 13:191-210.

Janzen, D. H. 1973. Comments on host-specificity of tropical herbivores and its relevance to species richness. Pages 201211 in V. H. Heywood, editor. Taxonomy and ecology. Academic Press, London, UK.

Johnson, S. D., and K. E. Steiner. 2000. Generalization versus specialization in plant pollination systems. Trends in Ecology and Evolution 15:140-143.

Jordano, P. 1987. Patterns of mutualistic interactions in pollination and seed dispersal: connectance, dependence, and coevolution. American Naturalist 129:657-677.

Kakutani, T., T. Inoue, M. Kato, and H. Ichihashi. 1990. In- 
sect-flower relationships in the campus of Kyoto University, Kyoto: an overview of the flowering phenology and the seasonal pattern of insect visits. Contributions of the Biological Laboratory, Kyoto University 27:465-521.

Kanstrup, J., and J. M. Olesen. 2000. Plant-flower visitor interactions in a neotropical rain forest canopy: community structure and generalisation level. Pages 33-42 in Ø. Totland, W. S. Armbruster, C. Fenster, U. Molau, L. A. Nilsson, J. M. Olesen, J. Ollerton, M. Philipp, and J. Agren, editors. Scandinavian Association for Pollination Ecology honours Knut Fægri. Norwegian Academy of Science and Letters 39, Oslo, Norway.

Kato, M. 1996. Plant-pollinator interactions in the understory of a lowland mixed dipterocarp forest in Sarawak. American Journal of Botany 83:732-743.

Kato, M., T. Kakutani, T. Inoue, and T. Itino. 1990. Insectflower relationship in the primary beech forest of Ashu, Kyoto: an overview of the flowering phenology and the seasonal pattern of insect visits. Contributions of the $\mathrm{Bi}$ ological Laboratory, Kyoto University 27:309-375.

Kato, M., M. Matsumoto, and T. Kato. 1993. Flowering phenology and anthophilous insect community in the cooltemperate subalpine forests and meadows at Mt. Kushigata in the central part of Japan. Contributions from the Biological Laboratory, Kyoto University 28:119-172.

Kato, M., and R. Miura. 1996. Flowering phenology and anthophilous insect community at a threatened natural lowland marsh at Nakaikemi in Tsuruga, Japan. Contributions from the Biological Laboratory, Kyoto University 29:1-48.

Kevan, P. G., 1970. High arctic insect-flower relations: The interrelationships of arthropods and flowers at Lake Hazen, Ellsmere Island, Northwest Territories, Canada. Dissertation. University of Alberta, Edmonton, Alberta, Canada.

Kress, W. J., and J. H. Beach. 1994. Flowering plant reproductive systems. Pages 161-182 in L. A. McDade, K. S. Bawa, H. A. Hespenheide, and G. S. Hartshorn, editors. La Selva. Ecology and natural history of a neotropical rain forest. University of Chicago Press, Chicago, Illinois, USA.

Legendre, P., F.-J. Lapointe, and P. Casgrain. 1994. Modeling brain evolution from behavior: a permutational regression approach. Evolution 48:1487-1499.

MacArthur, R. H. 1972. Geographical ecology. Harper and Row, New York, New York, USA.

Magaard, E. 1999. A macroecological analysis of plant-hummingbird community interactions. Thesis. University of Aarhus, Aarhus, Denmark.

Manly, B. F. J. 1991. Randomization and Monte Carlo methods in biology. Chapman and Hall, London, UK.

Martinez, N. D. 1991. Artifacts or attributes? Effects of resolution on the Little Rock Lake food web. Ecological Monographs 61:367-392.

McMullen, C. K. 1993. Flower-visiting insects of the Galapagos Islands. Pan-Pacific Entomologist 69:95-106.

Michener, C. D. 1954. Bees of Panama;. Bulletin of the American Museum of Natural History 104:1-176.

Momose, K., T. Yumoto, T. Nagamitsu, M. Kato, H. Nagamasu, S. Sakai, R. D. Harrison, T. Itioka, A. A. Hamid, and T. Inoue. 1998. Pollination biology in a lowland dipterocarp forest in Sarawak, Malaysia. I. Characteristics of the plant-pollinator community in a lowland dipterocarp forest. American Journal of Botany 85:1477-1501.

Mosquin, T., and J. E. Martin. 1967. Observations on the pollination biology of plants on Melville Island, N.W.T., Canada. Canadian Field-Naturalist 81:201-205.

Olesen, J. M. 2000. Exactly how generalised are pollination interactions? Pages 161-178 in Ø. Totland, W. S. Armbruster, C. Fenster, U. Molau, L. A. Nilsson, J. M. Olesen, J. Ollerton, M. Philipp, and J. Ågren, editors. Scandinavian Association for Pollination Ecology honours Knut Fægri. Norwegian Academy of Science and Letters 39, Oslo, Norway.

Olesen, J. M., L. I. Eskildsen, and S. Venkatasamy. $2002 a$.
Invasion of oceanic island-pollination networks: importance of invader complexes and endemic super generalists. Diversity and Distribution, 8, in press.

Olesen, J. M., A. Valido, and Y. L. Dupont. 2002b. Polinización de plantas canarias. El Indiferente 2 (La Laguna, Tenerife). Tenerife, Canary Islands.

Ollerton, J. 1996. Reconciling ecological processes with phylogenetic patterns: the apparent paradox of plant-pollinator systems. Journal of Ecology 84:767-769.

Ollerton, J. 1998. Sunbird surprise for syndromes. Nature 394: $726-727$.

Ollerton, J., and S. Watts. 2000. Phenotype space and floral typology: towards an objective assessment of pollination syndromes. Pages 149-159 in Ø. Totland, W. S. Armbruster, C. Fenster, U. Molau, L. A. Nilsson, J. M. Olesen, J. Ollerton, M. Philipp, and J. Ågren, editors. Scandinavian Association for Pollination Ecology honours Knut Fægri. Norwegian Academy of Science and Letters 39, Oslo, Norway.

Percival, M. 1974. Floral ecology of coastal scrub in southeast Jamaica. Biotropica 6:104-129.

Petanidou, T. 1991. Pollination ecology in a phryganic ecosystem. [In Greek.] Dissertation. Aristotelian University, Thessaloniki, Greece.

Polis, G. A. 1991. Complex trophic interactions in deserts: an empirical critique of food-web theory. American Naturalist 138: $123-155$.

Primack, R. B. 1983. Insect pollination in the New Zealand mountain flora. New Zealand Journal of Botany 21:317-333.

Proctor, M., P. Yeo, and A. Lack. 1996. The natural history of pollination. Harper Collins, London, UK.

Ramirez, N. 1989. Biología de polinización en una comunidad arbustiva tropical de la alta Guyana Venezolana. Biotropica 21:319-330.

Rasmussen, C., and J. M. Olesen. 2000. Oil flowers and oilcollecting bees. Pages 23-31 in Ø. Totland, W. S. Armbruster, C. Fenster, U. Molau, L. A. Nilsson, J. M. Olesen, J. Ollerton, M. Philipp, and J. Ågren, editors. Scandinavian Association for Pollination Ecology honours Knut Fægri. Norwegian Academy of Science and Letters 39, Oslo, Norway.

Reader, R. J. 1975. Competitive relationships of some bog ericads for major insect pollinators. Canadian Journal of Botany 53:1300-1305.

Ricklefs, R. E., and D. Schluter, editors. 1993. Species diversity in ecological communities. University of Chicago Press, Chicago, Illinois, USA.

Schemske, D., M. Willson, M. Melampy, L. Miller, L. Verner, K. Schemske, and L. Best. 1978. Flowering ecology of some spring woodland herbs. Ecology 59:351-366.

Schoenly, K., and J. E. Cohen. 1991. Temporal variation in food web structure: 16 empirical cases. Ecological Monographs 61:267-298.

Snow, B. K., and D. W. Snow. 1972. Feeding niches of hummingbirds in a Trinidad valley. Journal of Animal Ecology 41:471-485.

Sugihara, G., L.-F. Bersier, and K. Schoenly. 1997. Effects of taxonomic and trophic aggregation on food web properties. Oecologia 112:272-284.

Sugihara, G., K. Schoenly, and A. Trombla. 1989. Scale invariance in food web properties. Science 245:48-51.

Thompson, J. N. 1994. The coevolutionary process. University of Chicago Press, Chicago, Illinois, USA.

Waser, N. M., L. Chittka, M. V. Price, N. Williams, and J. Ollerton. 1996. Generalization in pollination systems, and why it matters. Ecology 77:1043-1060.

Wasserman, S., and K. Faust. 1994. Social network analysis: methods and applications. Cambridge University Press, Cambridge, UK.

Watts, D. J., and S. H. Strogatz. 1998. Collective dynamics of 'small-world' networks. Nature 393:440-442.

Whittaker, R. H. 1977. Evolution of species diversity in land communities. Evolutionary Biology 10:1-67. 